\title{
Phytoremediation Potential of Typha orientalis and Scirpus littoralis in Removal of Nitrogen and Phosphorus from Intensive Whiteleg Shrimp Wastewater
}

\author{
Ngo Thuy Diem Trang ${ }^{1, *}$, Lam Thi Nhu $\mathrm{Mo}^{1}$, Vo Chi $\operatorname{Linh}^{1}$, and Hans Brix ${ }^{2}$ \\ ${ }^{1}$ College of Environment and Natural Resources, Can Tho University, Vietnam \\ ${ }^{2}$ Department of Bioscience, Aarhus University, Ole Worms Allé, Building 1135, 8000 Aarhus C, \\ Denmark (hans.brix@biology.au.dk) \\ * Corresponding author's address: Can Tho University, College of Environment and Natural \\ Resources, Department of Environmental Sciences, Campus II, 3/2 Street, Ninh Kieu District, Can \\ Tho City, Vietnam. \\ Cell: +84 (0) 909243 703; Fax: +84 (292) 730392
}

\begin{abstract}
The rapid development of whiteleg shrimp farming in the Mekong delta of Vietnam has an adverse impact on the environment due to large amount of nitrogen and phosphorus content in wastewater and pond sludge/sediment. Phytoremediation is a promising technique to use plant for mitigating environmental impacts from intensively whiteleg shrimp culture. Growth responses, nitrogen and phosphorus removal of Typha orientalis and Scirpus littoralis were assessed at three water levels of +15 $\mathrm{cm},+30 \mathrm{~cm}$ and $+45 \mathrm{~cm}$. They were arranged in a completely randomized design with three replications. The plants were supplied wastewater from intensive whiteleg shrimp tanks once every two weeks. Waterlogged assessment was conducted for 71 days. Water levels significantly affected plant growth rate and nutrient removal capacity. S. littoralis grew well with a lower mortality rate and had no statistical reduction of biomass compared to $T$. orientalis at the highest water level of $+45 \mathrm{~cm}$. T. orientalis had the best perfromance in growth and biomass responses to waterlogged at water levels of $+15 \mathrm{~cm}$ and $+30 \mathrm{~cm}$. The results indicated that $S$. littoralis was the best of choice to grow in waterlogged condition of the shrimp pond for maintaining water quality.
\end{abstract}

\section{Introduction}

Total area and production of shrimp farming in Vietnam in 2013 was 655.156 hectare and 487.960 tonnes, in which the Mekong Delta (MD) $\left(8^{\circ} 33^{\prime}-10^{\circ} 55^{\prime} \mathrm{N}, 104^{\circ} 30^{\prime}-\right.$ $106^{\circ} 50^{\prime} \mathrm{E}$ ), South Vietnam, accounted for over $90 \%$ and $60 \%$ of Vietnamese shrimp

\footnotetext{
*Corresponding author: ntdtrang@ctu.edu.vn
} 
farming area and production [1]. Specifically, whiteleg shrimp (Litopenaeus vannamei) has increased rapidly in production in recent years, accounting for $38.16 \%$ of total shrimp production from $6.4 \%$ of the total farming area of the country. Planning to 2020, the MD will produce 310.000 tonnes and 60.000 ha of whiteleg shrimp farming. Anh et al. [2] reported that to produce 1 ton of shrimp $5.345-7.151 \mathrm{~m}^{3}$ wastewater, $259 \mathrm{~kg} \mathrm{BOD}, 769 \mathrm{~kg}$ COD, $1170 \mathrm{~kg}$ TSS, $30 \mathrm{~kg} \mathrm{~N}, 3.7 \mathrm{~kg} \mathrm{P}$ and $4.8 \mathrm{~kg} \mathrm{~N}-\mathrm{NH}_{3}$ were discharged into the environment. Shrimp aquaculture growth in Vietnam has suffered many problems which similar to Asia' situation in recent years. The major factors contributing to the problem in sustaining shrimp aquaculture are disease outbreaks, environmental degradation and poor management practice [3]. Poor water quality from the river is one of the causes in failure of 3.081 ha whiteleg shrimp [1]. Therefore, there is an urgent need to develop a more sustainable aquaculture industry that uses less water, and that does not deteriorate the water quality of the rivers. Phytoremediation is defined as the use of plants and their associated microbes for environmental clean-up [4]. One of the phytoremediation processes, in which plants are used to remove contaminants from soils or water into harvestable plant biomass, is called phytoextraction. Phytoextraction is used mainly for extracting heavy metals from polluted soils and water [5], but the use of plant uptake and plant-mediated conversions also has great potential for the removal of nutrients from nutrient enriched waters.

In the present study, Scirpus littoralis Schrab and Typha orientalis C. Presl were chose to study on waterlogged stress. In fact, $T$. orientalis and $S$. littoralis are cultivated in the paddy field and/or in the shrimp ponds in the MD for human food and providing habitat for shrimp, respectively. To understand the potential effects of increased water levels on these aquatic macrophytes, information is needed regarding the duration and water regime exposure in relation to the response of the plant species in term of growth, biomass and nutrient removal. Therefore, the present study was carried out to identify waterloggedtolerant species through survival, growth, biomass and nitrogen $(\mathrm{N})$ and phosphorus $(\mathrm{P})$ removal with the hypothesis that $S$. littoralis had better performance than that of $T$. orientalis.

\section{Materials and Methods}

\subsection{Experimental Setup}

A completely randomized design consisting of two plant species (Scirpus littoralis Schrab and Typha orientalis C. Presl) and three water levels $(+15,+30$ and $+45 \mathrm{~cm})$ was set up in triplicates. The corresponding unplanted containers were filled with three water levels of $+15,+30$ and $+45 \mathrm{~cm}$ which were considered as control treatments. The experiment was conducted in the greenhouse at the College of Environment and Natural Resources of Can Tho University, Vietnam $\left(10.03^{\circ} \mathrm{N}\right.$ latitude and $105.76^{\circ} \mathrm{E}$ longitude).

\subsection{Plant Materials and Growth Condition}

Rhizomes and young plants of the two studied species were collected from the fields. The plastic containers with the size of $50-\mathrm{L}, 45-\mathrm{L}$ and $120-\mathrm{L}$ were filled with a $25-\mathrm{L}, 30-\mathrm{L}$ and 80 - $\mathrm{L}$ of wastewater that made up water levels at $+15,+30$ and $+45 \mathrm{~cm}$ above sediment, respectively. Sixteen $\mathrm{kg}$ of sediment $(76.2 \%$ dry weight) from the intensive whiteleg shrimp pond was filled in each container to mimic the bottom pond condition. The individual young and similar size plants of each species were placed in the container for acclimation two months before flooding. The plants were thinned out to keep a density of 15 plants $/ \mathrm{m}^{2}$ 
[6]. Wastewater from the intensive whiteleg shrimp culture tanks with stocking density of 400 shrimps $/ \mathrm{m}^{3}$ water that were used as growth solution for the plants. A valve connected with $\varnothing 34 \mathrm{~mm}$ PVC tube was fitted through a hole in the side of the containers at the middle of water level to sample water (Figure. 1).
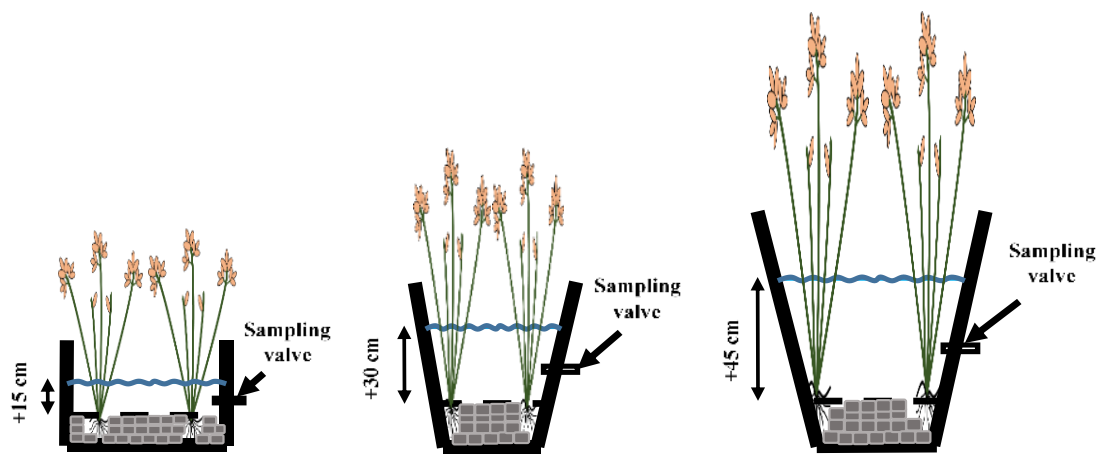

Fig.1. An overview of the treatment plots which represented one plant species for theree water levels of $+15,+30$ and $+45 \mathrm{~cm}$ above sediment

\subsection{Plant Growth and Biomass Measurement}

At harvest, plants were carefully removed from the sediment and the roots were carefully washed to remove particle and sediment. The fractions were weighed for fresh biomass and dried at $60^{\circ} \mathrm{C}$ until constant weight to determine for dry weight. Relative growth rate of biomass was calculated from the difference of natural logarithm of harvested biomass and beginning biomass divided by time.

\subsection{Water Sampling and Analysis}

Water samples were taken every two weeks at 6:00 - 7:00 AM. Temperature $\left({ }^{\circ} \mathrm{C}\right)$, dissolved oxygen $(\mathrm{DO}, \mathrm{mg} / \mathrm{L})$, redox potential $\left(\mathrm{E}_{\mathrm{h}}, \mathrm{mV}\right)$ of the water in the containers were measured at the experimental site using respective portable meters. Water samples were collected and transferred immediately to the laboratory for analysis of $\mathrm{COD}, \mathrm{NH}_{4}-\mathrm{N}, \mathrm{NO}_{2}-$ $\mathrm{N}, \mathrm{NO}_{3}-\mathrm{N}, \mathrm{TKN}, \mathrm{PO}_{4}-\mathrm{P}$ and TP. All the analytical measurements were carried out according to Standard Methods [7].

\subsection{Statistical Analysis}

Data were tested for normal distribution, variance homogeneity (Levene's test) and logarithmically transformed if necessary. Differences in water quality were identified by two-way repeated measures ANOVA (General Linear Models) using Type III sum of squares. Differences in plant growth and biomass were identified by one-way ANOVA. Tukey Honestly Significant Differences (HSD) was used to compare significant differences between treatments at the 5\% probability level. The software Statgraphics Centurion XV (StatPoint, Inc., USA) was used for all statistical analyses. 


\section{Results and Discussions}

\subsection{Plant Growth and Biomass Allocation}

Water levels significantly affected plant survival rate, number of new shoot and root length ( $\mathrm{p}<0.05$; Figs. $2 \mathrm{~A}, 2 \mathrm{~B}, 2 \mathrm{C}$ ), but did not affect plant height and growth rate of shoot and root ( $>0.05$; Fig. 2). The same findings in Typha domingensis when the plants were flooded at 40-137 cm depth for six weeks [8]. T. orientalis in the water level of $+45 \mathrm{~cm}$ showed stress symptom of leaf rolling and wilting at the $6^{\text {th }}$ week of waterlogged, and the major part of shoots eventually dried out at the $10^{\text {th }}$ week of waterlogged. Therefore, at the harvest we counted the number of survival plant for $T$. orientalis in the water level of +45 $\mathrm{cm}$ which was zero due to no green leaves, but number of new shoot and biomass of those plants was collected and measured. S. littoralis had an average of $21 \%$ mortality at the water level of $+45 \mathrm{~cm}$ (Figure. 2A). Although two tested species have been known as wetlands plants and they were grown in the commercial extensive shrimp pond in the MD, they both showed stress of waterlogged at the water level of $+45 \mathrm{~cm}$. It can be explained that the growth condition with sallow sediment layer with low nutrient concentration in the sediment and in the wastewater, which might cause unfavorable condition for plant growth [9].
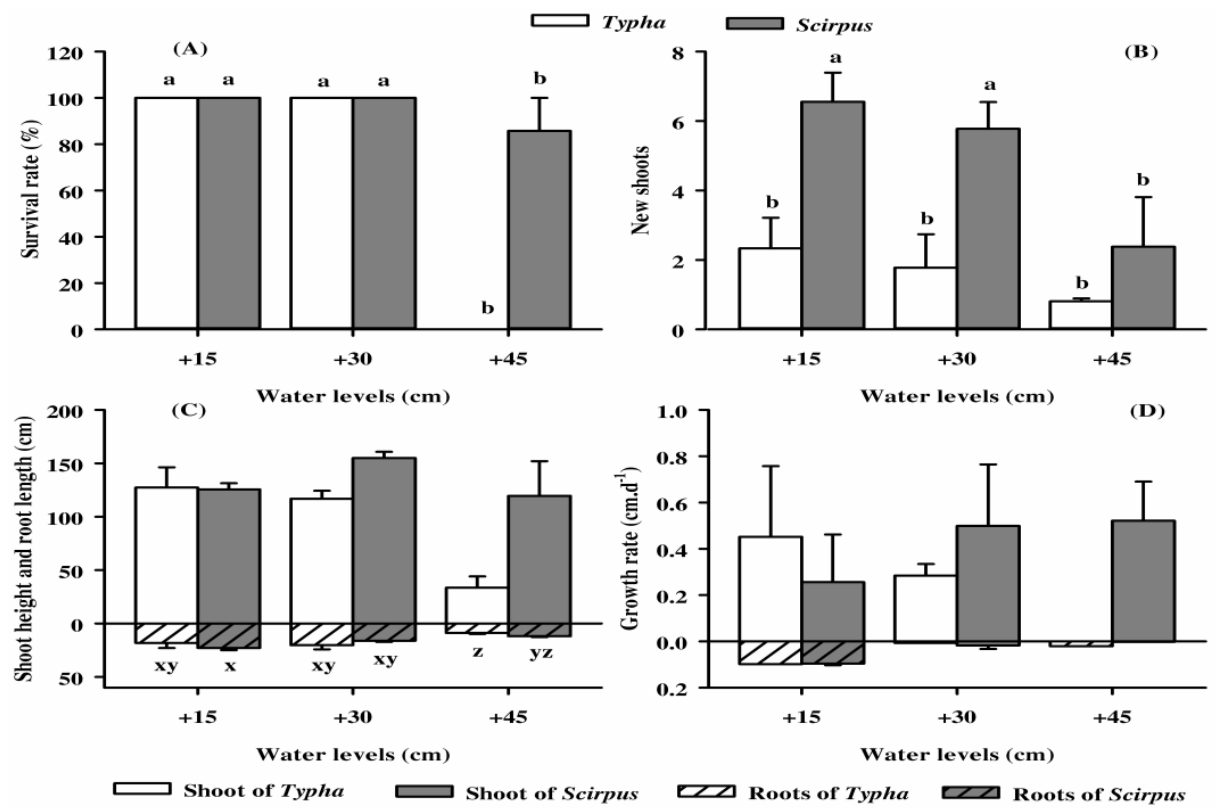

Fig. 2. Survival rate $(\%, A)$, number of new shoot (B), shoot height and root length $(C)$ and growth rate of shoot and root (D) of T. orientalis and S. littoralis grown at different water levels. Values are the means of 3 replicates \pm S.D. Different letter ${ }^{a, b, x, y}$ indicates significant difference based on a Tukey HSD test $(\mathrm{p}<0.05)$.

Number of new shoots of $S$. littoralis was higher than that of $T$. orientalis in all water levels and it was also reduced at the highest water level of $+45 \mathrm{~cm}(\mathrm{p}<0.05$; Figure. $2 \mathrm{~B})$. The root length of both species tended to be shortened at the highest water level of $+45 \mathrm{~cm}$ $(\mathrm{p}<0.05$; Figure. $2 \mathrm{C})$. Between two tested species $S$. littoralis showed more tolerant to waterlogged condition in term of survival. Grace [10] and Newman et al. [9] reported that 
nutrient enrichment and shallow water depths (i.e., $20-30 \mathrm{~cm}$ ) were usually favor the dominance of Typha species in wetlands. While T. latifolia and $T$. domingensis can grow at a wide range of water depths $(0-115 \mathrm{~cm})$, these species have high shoot density and flowering incidence only within a narrow range of water depths [10]. As water depth increases, $T$. domingensis increases its shoot height, produces fewer but larger ramets, and decreases the incidence of flowering. Increasing water depth reduces the anchorage capacity of plants by decreasing biomass allocation to rhizomes and roots [10]. Water levels significantly affected shoot and root dry and fresh weight at the harvest of the two species $(p<0.05$; Figure. 3$)$ but did not affect relative growth rate (RGR) of their biomass $(\mathrm{p}>0.05)$. The species factor also influenced fresh weight and dry weight of the shoots and the roots. Although the biomass was reduced in both species in response to water levels $(\mathrm{p}<0.05)$, it nevertheless was significantly greater in $T$. orientalis than $S$. littoralis under $+30 \mathrm{~cm}$ water levels $(\mathrm{p}<0.05) S$. littoralis showed no statistical reduction in fresh weight and dry weight of the shoot and the root fractions across water levels while $T$. orientalis had a reduction of these parameters at the highest water level of $+45 \mathrm{~cm}$.
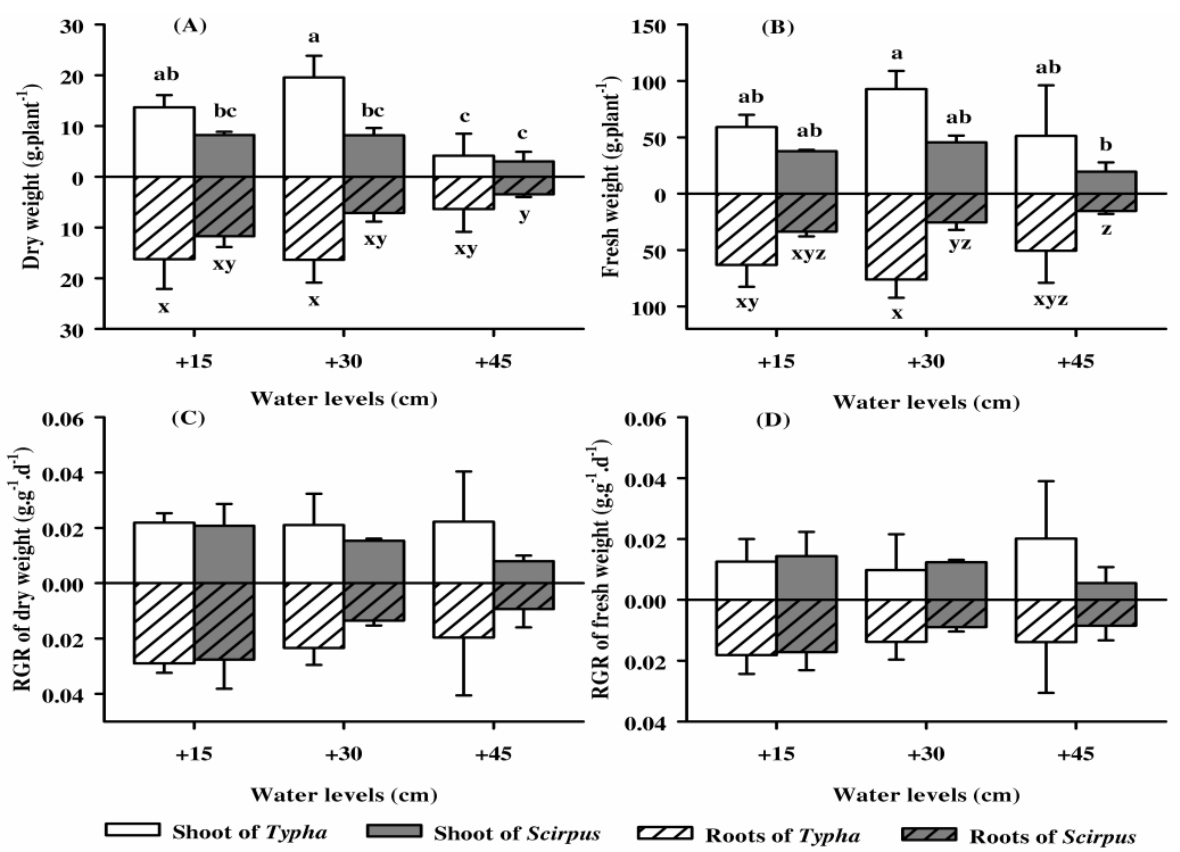

Fig. 3. Dry weight (A), fresh weight (B), relative growth rate (RGR) of dry weight (C) and fresh weight (D) of T. orientalis and S. littoralis grown at different water levels. Values are the means of 3 replicates \pm S.D. Different letter a,b indicates significant difference between treatment in the shoot fractions based on a Tukey HSD test $(\mathrm{p}<0.05)$. Different letter ${ }^{x, y}$ indicates significant difference between treatment in the root fractions based on a Tukey HSD test $(p<0.05)$. 


\subsection{Water Quality in the Growth Containers}

\subsubsection{Dissolved Oxygen, Redox Potential, Temperature and Chemical Oxygen Demand Values in the Water}

There were significant differences for dissolved oxygen (DO), redox potential $\left(E_{h}\right)$, temperature and chemical oxygen demand (COD) in the water between treatments and between sampling times $(\mathrm{p}<0.05$; Figure. 4$)$. Dissolved oxygen is the most critical water quality for shrimp growth. The DO concentrations tended to increase over time $(\mathrm{p}<0.05$; Figure. 4A) and was at the lowest value in the containers planted T. orientalis at the water level of $+45 \mathrm{~cm}(\mathrm{p}<0.05$; Fig. $4 \mathrm{~A})$. Although the water DO concentration was the lowest in the treatment of $T$. orientalis at $+45 \mathrm{~cm}$ water level but it was higher than that of the permitted limit $(\geq 3.5)$ for requirement on shrimp rearing water quality regarding to Appendix 1 of the Vietnamese standards No. 02-19/2014/BNNPTNT (issued on July 29, 2014) [11]. In the case of submerged sediment in our study, penetration of atmospheric oxygen into the sediment was limited due to low rates of oxygen diffusion and, hence, low redox potential, which inhibits plant growth through inhibition of respiration and production of toxins in reducing conditions. Therefore, the reported water redox potential values had similar trend to DO concentration, it increased over time and had the highest values at the end of the study $(p<0.05$; Figure. $4 B)$. The average values of $E_{h}$ in the water of the treatments were in the range of -101 to $-75 \mathrm{mV}$ and were classified as reduced environment [12].
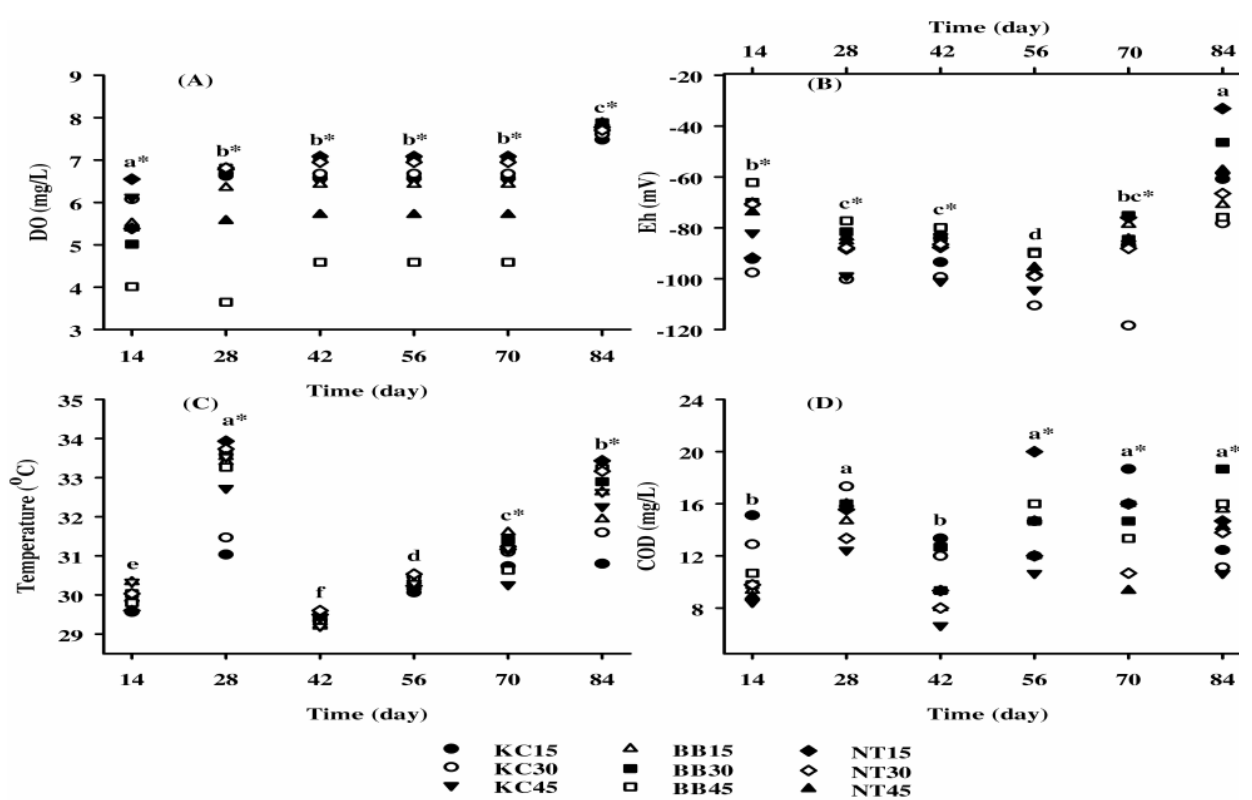

Fig. 4. Dissolved oxygen (A), redox potential (B), temperature (C) and chemical oxygen demand (D) in the water over time of $T$. orientalis $(\mathrm{BB}), S$. littoralis $(\mathrm{NT})$ and unplanted $(\mathrm{KC})$ at $+15,+30$ and $+45 \mathrm{~cm}$ water levels. Values are the means of 3 replicates. Asterisk $\left({ }^{*}\right)$ indicates significant difference between treatments within sampling time. Different letter ${ }^{\mathrm{a}, \mathrm{b}, \mathrm{c}}$ indicates significant difference between sampling times based on a Tukey HSD test $(\mathrm{p}<0.05)$.

The average water temparature of the treatments were in the range of $30.3-31.4^{\circ} \mathrm{C}$ (Figure. 4C) which was in the permitted limit $\left(18.0-33.0^{\circ} \mathrm{C}\right)$ for requirement on shrimp 
rearing water quality (Vietnamese standards No. 02-19/2014/BNNPTNT). COD was not listed in the former Circular No. 45/2010/TT-BNNPTNT [13] for permitted limit in water quality for shrimp growth or in discharged water; however, in the updated Vietnamese standards [11] COD parameter was placed in the permitted limit for discharge effluent after treatment of wastewater $(\leq 150 \mathrm{mg} / \mathrm{L})$. In our study, COD concentrations in all the treatments fluctuated and tended to increase at the end of the study, but they were 6-times lower than that of the permitted limit. In sum, DO, temperature and COD concentrations in the water across the treatments meet the Vietnamese standards requirement on shrimp rearing water quality. The water in the treatments was qualified and can be reused for rearing shrimp.

\subsubsection{Nitrogen and Phosphorus Concentrations in the Water}

Nitrite nitrogen $\left(\mathrm{NO}_{2}-\mathrm{N}\right)$ is toxic to shrimp and exposure to high concentrations may cause retarded growth and mortalities [14]. The average $\mathrm{NO}_{2}-\mathrm{N}$ concentrations in the treatments tended to reduce over time and increase again at the last sampling time $(\mathrm{p}<0.05$; Figure. 5A). Similar trend was observed in $\mathrm{NO}_{3}-\mathrm{N}, \mathrm{NH}_{4}-\mathrm{N}$ and $\mathrm{TKN}$ concentrations $(\mathrm{p}<0.05$; Figure. 5B, 5C \& 5D) that reflected debris of plants and microorganism body degraded causing water re-pollution at the end of the study. In general, water $\mathrm{NO}_{2}-\mathrm{N}$ concentrations in the treatments were in the range of $0.03-0.3 \mathrm{mg} / \mathrm{L}$ which was within the permitted range for normal shrimp growth (Circular No. 45/2010/TT-BNNPTNT, $<0.35$ $\mathrm{mg} / \mathrm{L}$ ) [13]. However, $\mathrm{NO}_{2}-\mathrm{N}$ concentration the in the unplanted treatments was slightly higher which was the same finding reported by Doan et al. [6] who using constructed wetlands planted Typha orientalis to purify intensive white leg shrimp waste water. Gross et al. [14] suggested a safe concentration for whiteleg shrimp production in the ponds to be less than $0.45 \mathrm{mg} / \mathrm{L} \mathrm{NO}_{2}-\mathrm{N}$. The $\mathrm{NO}_{3}-\mathrm{N}$ concentration is not harmful for shrimp growth; however, higher accumulation of $\mathrm{NO}_{3}-\mathrm{N}$ might be toxic to shrimp [15]. In this study, $\mathrm{NO}_{3}$ $\mathrm{N}$ concentration likely reduced overtime for all treatments, except for the last sampling, and were negligible ranging from 0.14 to $0.37 \mathrm{mg} / \mathrm{L}$. The $\mathrm{NH}_{4}-\mathrm{N}$ concentrations in the treatments were in the range of $0.3-0.8 \mathrm{mg} / \mathrm{L}$ in which the planted treatments had the lower $\mathrm{NH}_{4}-\mathrm{N}$ concentrations compared to in the unplanted treatments $(\mathrm{p}<0.05$; Fig. 5C). The planted treatments with +15 and $+30 \mathrm{~cm}$ water levels had lower $\mathrm{NH}_{4}-\mathrm{N}$ concentrations because the plants grew well in these treatments resulting in a better $\mathrm{NH}_{4}-\mathrm{N}$ uptake rate by the plants leading to the lower TKN concentrations.

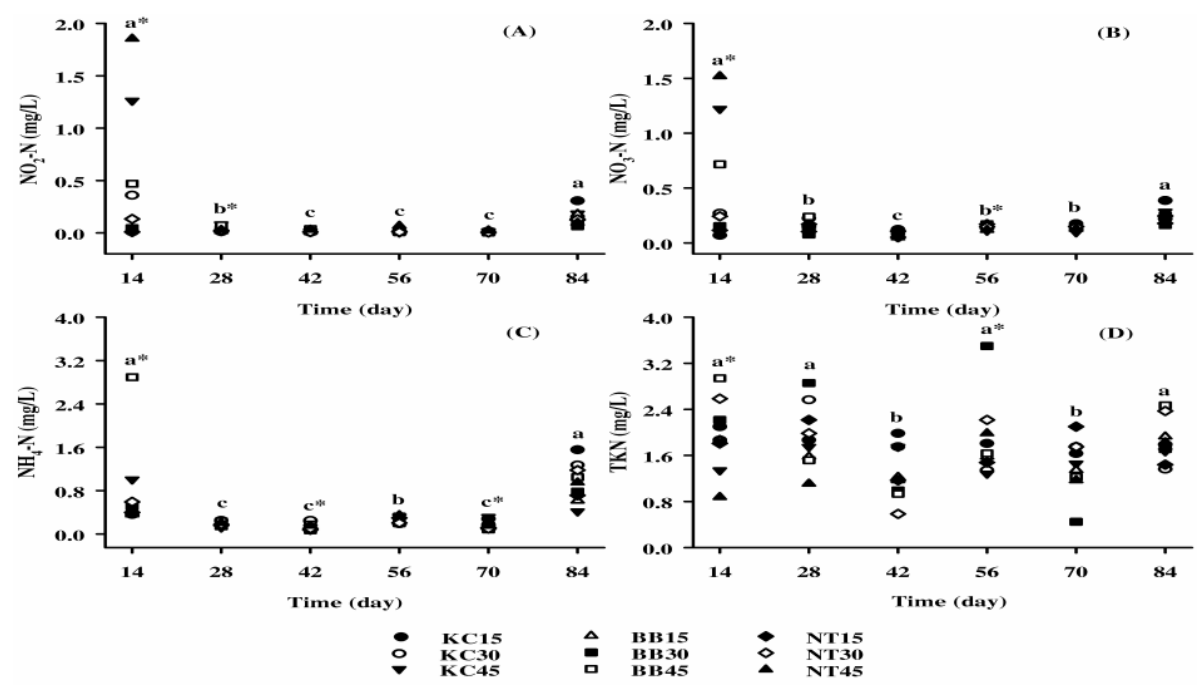


Fig. 5. Nitrite nitrogen (A), nitrate nitrogen (B), ammonium nitrogen (C) and total kjeldahl nitrogen (D) in the water over time of $T$. orientalis (BB), S. littoralis (NT) and unplanted (KC) at $+15,+30$ and $+45 \mathrm{~cm}$ water levels. Values are the means of 3 replicates. Asterisk $\left(^{*}\right)$ indicates significant difference between treatments within sampling time. Different letter ${ }^{\mathrm{a}, \mathrm{b}, \mathrm{c}}$ indicates significant difference between sampling times based on a Tukey HSD test $(\mathrm{p}<0.05)$.

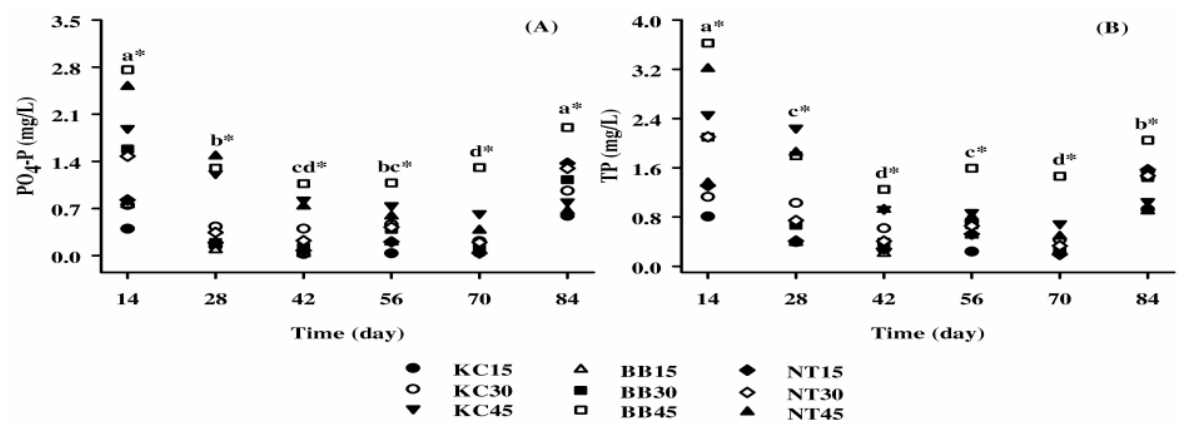

Fig. 6. Orthophosphate (A) and total phosphorus (B) in the water over time of T. orientalis (BB), $S$. littoralis (NT) and unplanted (KC) at $+15,+30$ and $+45 \mathrm{~cm}$ water levels. Values are the means of 3 replicates. Asterisk $\left(^{*}\right)$ indicates significant difference between treatments within sampling time. Different letter ${ }^{a, b, c}$ indicates significant difference between sampling times based on a Tukey HSD test $(\mathrm{p}<0.05)$.

The concentrations of $\mathrm{PO}_{4}-\mathrm{P}$ and TP of all the treatments reduced over time but increased at the last sampling point $(\mathrm{p}<0.05$; Figure. $6 \mathrm{~A} \& 6 \mathrm{~B})$. There were significant differences between the treatments within sampling time. Although $\mathrm{P}$ is not harmful to aquatic animals, $\mathrm{P}$ supports algae and aquatic plants growth [16]. In sum, water quality parameters across the treatments meet the Vietnamese standards requirement on shrimp rearing water quality. The treatments with plants helped to maintain better quality than that of the unplanted treatments.

\section{Conclusion}

The treatment with presence of plants helped to maintain a better water quality than that in the unplanted treatments. The results indicated that $S$. littoralis was the best of choice to grow in waterlogged condition of the shrimp pond for maintaining water quality. However, further studies must be conducted using a commercial shrimp pond or a settlement pond to grow $S$. littoralis together and/or separate to further assess the feasibility of using this species.

\section{Acknowledgments}

This work was financially supported by the project grant B2016-TCT-10ĐT from Ministry of Education and Training of Vietnam.

\section{References}

1. Directorate of Fisheries, Reportat the Seminar on Shrimp Aquaculture Development Strategyin Vietnam, $6^{\text {th }}$ August 2013, Bac Lieu, Vietnam, 12 pages (2013) 
2. P.T. Anh, C. Kroeze, S.R. Bush, A.P. J. Mol, Agr. Water Manage 97, 6 (2010)

3. J.H. Primavera, Tropical mariculture (Academic Press, San Diego, 1998)

4. E. Pilon-Smits, Ann. Rev. Plant Biol., 56 (2005)

5. P.B.A.N. Kumar, V. Dushenkov, H. Motto, I. Raskin, Environ. Sci. Technol 29 (1995)

6. N.P.N. Doan, L.T.N. Mo, N.T.D. Trang,Can Tho University J. of Sci (in English) 2 (2016)

7. American Public Health Association (APHA), Standard methods for the examination of water and wastewater (Washington D.C., USA, 1998)

8. H. Chen, M.F. Zamorano, D. (Ivanoff, Wetlands, 2010)

9. S. Newman, J.B. Grace, J.W. Koebel, Ecol. Appl 6 (1996)

10. J.B. Grace, Am. J. Bot 76 (1989)

11. Ministry of Agriculture and Rural Development (MARD), Vietnamese standards No. 02-19/2014/BNNPTNT (issued on July 29, 2014)

12. I.S. Kaurichev, V.S. Shishova, Sov. Soil Sci 5 (1967)

13. Ministry of Agriculture and Rural Development (MARD), Circular No. 45/2010/TTBNNPTNT (issued on July 22, 2010)

14. A. Gross, S. Abutbul, D. Zilberg. J. of the world aquacult. Soc 35, 3 (2004)

15. D.D. Kuhn, S.A. Smith, G. J. Flick, Glob. Aquacult. Advocate (2011)

16. N.T.D. Trang, D. Konnerup, H. Brix, Aquacult. Eng. 78 (2017) 